\title{
Literatura e cultura: do nacional ao transnacional
}

\section{Luiz Gonzaga Marchezan}

To cite this article: Luiz Gonzaga Marchezan (2016) Literatura e cultura: do nacional ao transnacional, Hispanic Research Journal, 17:1, 84-85, DOI: 10.1080/14682737.2015.1125110

To link to this article: https://doi.org/10.1080/14682737.2015.1125110

\section{冓 Published online: 01 Mar 2016.}

Submit your article to this journal $\pi$

Џ Article views: 26

View Crossmark data ¿ 
'inextricable' are serially misapplied, as are the terms 'paradox' and 'paradoxical', which are often employed to describe simple inconsistency. There are a significant number of typographical errors. In sum, this study does not provide a particularly auspicious curtain-raiser to Cortázar's centenary year.

\section{Christ Church, Oxford}

DOMINIC MORAN

Literatura e cultura: do nacional ao transnacional. By José Luís JoBIm. RIO DE JANEIRo: EDUERJ. 2OI3. Pp. 2I4. ISBN: 9788575 II 27 I7

Este livro, recém-lançado pelo professor José Luís Jobim, da Universidade Estadual do Rio de Janeiro, constitui mais uma iniciativa da Coleção Brasil/Itália estabelecida entre a instituição de origem do autor e a Universidade de Roma La Sapienza. O livro, dividido em dez capítulos, deixa ainda mais vigorosa a contribuição do autor para o estudo dos conceitos de nacionalismo, identidade e globalização.

O livro tem ainda o mérito de, no bojo de suas considerações, realizar, com método, uma análise inovadora da contribuição do pensamento crítico de Mário de Andrade (I893-I945) que, marcadamente, quer em sua epistolografia, quer em seus ensaios, exercitou, entre pares, por toda sua vida, um pensamento orientado para a construção de um projeto de aquisição de competência para a produção cultural no país. Segundo o professor Jobim, um pensamento no âmbito dos conceitos de nacionalismo, identidade e globalização já transparece, bem apurado, nos escritos de Mário de Andrade, considerado também por ele, no capítulo final do volume, um memorialista, pelo modo como, entre décadas, constatou e avaliou 'trocas e transferências literárias e culturais' (p. 205), próprias das análises que promoveu - conscientes, orgânicas, no conjunto múltiplo do ideário modernista.

Jobim também resgata, com precisão, os debates críticos de Mário de Andrade acerca de influências culturais que aconteceram, de forma marcada, a partir do Romantismo brasileiro, também expressa na sua obra ficcional mais importante - Macunaíma - por meio do perfil 'transnacional' (p. I67), sem traços geográficos da personagem. Para o docente, os modernistas e, entre eles, o memorialista Mário de Andrade, trouxeram nas suas inquietações uma atitude invariante 'no procedimento, na metodologia, na atitude do artista em relação ao que produzia' (p. 208), cônscios, de acordo com a palestra memorável de Mário de Andrade ('O movimento Modernista'), de um 'direito permanente à pesquisa estética', da necessidade de uma 'atualização da inteligência artística brasileira' e da 'estabilização de uma consciência criadora nacional' para a produção de bens culturais sustentados tanto em paradigmas nacionais como transnacionais (p. 208).

As considerações precisas de Literatura e cultura: do nacional ao transnacional movimentam-se a partir da ideia de nacionalidade no 'sentido abrangente de lugar' (p. 20), que, no Brasil, é resultante de vivências num território assentado como colônia. Das atitudes literárias locais românticas e de vanguardas, futuras, o autor, como historiador, lastreia as experiências literárias nacionais e, nelas, suas questões identitárias típicas. Temos, depois, no ensaio, fora dos limites da cultura brasileira, as considerações pertinentes acerca da 'autoconsciência dos agentes literários sobre seu próprio trabalho' e sobre 'a percepção e valorização do novo na literatura' (p. 35).

Por esses caminhos, o volume traz um conjunto de conhecimentos preciosos, repensando o conceito de identidade a partir dos lugares históricos em que o sujeito, o 
agente literário, ancorado no tempo, promove sua interpretação do mundo, envolvido com sua subjetividade e com sua trajetória no processo histórico vivido. Assentam-se, assim, as considerações do capítulo três no âmbito da discussão da formação de uma identidade nacional, balizada entre noções de pertença e escolha pessoal. De modo equilibrado, esse magnífico capítulo traz uma medida para o entendimento da identidade nacional no interior de uma noção de pertença considerada como uma 'autodeterminação coletiva' (p. 60) e de acordo com um senso comum acerca de convivência social e de noções individuais e coletivas.

O conceito de cultura, entendido como um complexo de atividades sócio-políticoculturais, introduz discussões e ponderações relativas ao conceito de globalização, até porque o docente analisa a questão 'Crise na Cultura' no âmago do contexto vigente da globalização.

Desse modo, o historiador interpreta lucidamente a diversidade cultural em seus vários ambientes, diante da assimetria com que trocas de bens culturais acontecem, passando por 'questões de autoidentidades das diversas sociedades humanas' (p. 73). A globalização, argumenta Jobim, movida pelas noções de mercado, não reconhece a cultura do outro e, assim, as nações economicamente fracas proporcionam o surgimento de "estruturas de replicação que internalizam estas categorias do "belo" ou do "bom" e visam produzir bens culturais que correspondem a elas' (p. 76).

A globalização, ainda segundo Jobim, consolidou 'blocos transnacionais, mais ou menos formalizados, que dão um novo sentido às trocas e transferências literárias e culturais' (p. I08) e estes, dessa maneira, impuseram ao mundo 'novas formas de convivência política, econômica e cultural, novas entidades que vão além do apenas nacional, novas instituições transnacionais' (p. I23), que estabelecem uma espécie de mercado comum no qual os bens culturais comuns não são trocados do ponto de vista de uma parceria entre blocos com identidades culturais diferentes, mas entre poderes econômicos afinados.

Universidade Estadual Paulista (UNESP)

Luiz GonZaga MarcheZan

Brazilian Jive: From Samba to Bossa and Rap. By David Treece. London: Reaktion Books, USA distribution by University of Chicago Press. 20I3. Pp. 232. ISBN: 978 I 780230856

The title under review is the third in the Reverb Series of books on the contexts and aesthetics of music-making. Given the prominence of song and dance music in Brazil's expressive culture and the nation's outstanding position in the international musical imaginary, it makes perfect sense to move forward with a release such as the present one. David Treece has been probing Brazilian popular music since $c$. I990 and has published bi-annual studies - concerning the internationalization of Brazilian sounds, models of song analysis, so-called 'protest music', the sophistication of Bossa Nova, subsequent inventive songwriters, and, more recently, Afro-Brazilian themes - as journal articles or segments in edited volumes. As the book's content is largely drawn from those sources, those who follow scholarship in this area-studies specialty will likely be familiar with much of the material. This profile, however, does not impede the collection from standing tall on its own: only one segment is identical to its first iteration; examples and parts of 